\title{
Pulmonary manifestations of inflammatory bowel disease
}

\author{
Sebastian Majewski, Wojciech Piotrowski
}

Department of Pneumology and Allergy, Medical University of Lodz, Lodz, Poland

Submitted: 18 June 2013

Accepted: 3 January 2014

Arch Med Sci 2015; 11, 6: 1179-1188

DOI: $10.5114 /$ aoms.2015.56343

Copyright $\odot 2015$ Termedia \& Banach

\section{Abstract}

Bronchopulmonary signs and symptoms are examples of variable extraintestinal manifestations of the inflammatory bowel diseases (IBD). These complications of Crohn's disease (CD) and ulcerative colitis (UC) seem to be underrecognized by both pulmonary physicians and gastroenterologists. The objective of the present review was to gather and summarize information on this particular matter, on the basis of available up-to-date literature. Tracheobronchial involvement is the most prevalent respiratory presentation, whereas IBD-related interstitial lung disease is less frequent. Latent and asymptomatic pulmonary involvement is not unusual. Differential diagnosis should always consider infections (mainly tuberculosis) and drug-induced lung pathology. The common link between intestinal disease and lung pathology is unknown, but many hypotheses have been proposed. It is speculated that environmental pollution, common immunological mechanisms and predisposing genetic factors may play a role.

Key words: inflammatory bowel disease, ulcerative colitis, Crohn's disease, tracheobronchitis, interstitial lung disease.

\section{Introduction}

The term inflammatory bowel disease (IBD) is frequently used to describe two distinct diseases: ulcerative colitis (UC) and Crohn's disease (CD). The incidence in developed countries is up to 24/100 000/year (for UC in Europe), with prevalence as high as 505 and 322/100 000/year for UC and CD, respectively [1]. The most widely accepted etiological concept is that IBD results from an inappropriate immune response to physiologic gut flora in a genetically susceptible host [2]. Each entity has its discriminating clinical and morphological features, but in about $10 \%$ of patients a clear differential diagnosis is not possible. The systemic character is one of the most important common clinical attributes. The best acknowledged extraintestinal manifestations of IBD, usually related to the disease exacerbations, are uveitis, conjunctivitis, arthritis and erythema nodosum. Primary sclerosing cholangitis, hemolytic anemia, Hashimoto's disease and other diseases of autoimmunologic origin are frequent co-morbidities, and may appear independently of the bowel disease activity [3]. Rankin et al. reported that among 569 patients with CD, 24\% had a history of at least one extraintestinal manifestation, which was more frequent in patients with ileocolitis and perianal location in comparison to those with isolated small bowel disease [4]. Similar numbers were reported for UC. However, the frequency and distribution of specific manifestations seem to be different between these two diseases [5]. In

\author{
Corresponding author: \\ Wojciech Piotrowski MD, PhD \\ Department of Pneumology \\ and Allergy \\ Medical University of Lodz \\ 22 Kopcinskiego St \\ 90-153 Lodz, Poland \\ Phone: +48426782129 \\ Fax: +48 426782129 \\ E-mail:wojciech.piotrowski@ \\ umed.lodz.pl
}


general, IBD patients report frequent respiratory symptoms [6, 7].

A PubMed database search was planned with the entries comprising compositions of the following keywords: "inflammatory bowel disease", "ulcerative colitis", "Crohn's disease”, "lung”, "pulmonary manifestations", "tracheobronchial disease", and "interstitial lung disease". The authors' final selection of articles directly related to the objective of the review included 135 papers (106 case reports and case series, 17 original research papers, 9 reviews, and 3 meta-analyses). Below, pulmonary manifestations of IBD are extensively discussed on the basis of available literature. The multidisciplinary approach to this topic, with special regard to clinical aspects, radiology, histopathology and treatment, was applied.

\section{Tracheobronchial involvement}

\section{Clinical presentation}

Several cases of coexistence of IBD and bronchiectasis [8-14], bronchitis, tracheobronchitis $[8,12,15-20]$ and bronchiolitis [19, 21, 22] have been reported. None of these complications are specific for either UC or CD; however, the majority of cases concern abnormalities in proximal or distal conducting airways in UC. Colobronchial [23] and oesophago-pulmonary [24] fistulas have been reported in CD. Symptoms of airway involvement may precede the first symptoms of bowel disease by years [10, 21], but most often they appear in patients with a long-lasting history of IBD. Respiratory symptoms may accompany exacerbations of IBD [10,12], but most typically they are not parallel to exacerbations, and may show up during remissions or quiescent periods $[15,18]$. Such coincidence with surgical treatment of bowel disease (colectomy, proctectomy, ileostomy) has been reported $[8,12,17,19,25]$. Signs of tracheobronchial involvement may appear days to months after surgery.

Patients with central airway involvement usually report productive or non-productive cough, wheezing, shortness of breath, limitations of exercise, purulent expectoration, hemoptysis or chest pain. Asthma is frequently recognized, and anti-asthmatic treatment is typically started, but the control of symptoms is variable.

\section{Lung function tests}

Several authors have reported abnormal lung function test results in about $40-60 \%$ of asymptomatic patients, with limited airflow in peripheral airways being the most prevalent pattern $[14,26$, 27]. Mild to severe bronchial obstruction has also been reported [17, 19, 21, 28]. Individual cases presenting signs and symptoms of tracheobronchial in- volvement may have normal spirometry [12]. In the study of Louis et al. [29], 41\% of patients with IBD after subtracting patients with coexisting atopy had a positive methacholine test result (compared to 5\% in the control group). Peradzyńska et al. [13] reported positive methacholine challenge tests in about $15 \%$ of children suffering from IBD without pulmonary symptoms. Fractional exhaled nitric oxide (FeNO) is frequently elevated in asymptomatic IBD patients $[13,30]$. The most probable explanation for these findings is latent inflammation of the bronchial tree. As indicated by Louis et al. [31], patients with $C D$ have increased numbers of eosinophils in induced sputum. However, the intensity of eosinophilic inflammation did not correlate with the degree of forced expiratory volume in $1^{\text {st }}$ of expiration $\left(\mathrm{FEV}_{1}\right)$ fall after methacholine inhalation, suggesting that this phenomenon is not related to eosinophilic infiltration. A positive methacholine test may cause problems in differential diagnosis between IBD-related tracheobronchial pathology and true asthma. A positive reversibility test and a very good response to inhaled steroids may indicate asthma rather than IBD-related tracheobronchitis. On the other hand, a negative methacholine test excludes asthma. The differential diagnosis may be even more problematic in view of the fact that atopy is more frequent among IBD patients than healthy controls [32].

A lung function test in patients with bronchiolitis may reveal severe bronchial obstruction non-responsive to bronchodilators [19], but in other patients mild obstruction or normal spirometry was detected [22]. Diffusing capacity for carbon monoxide (DLCO) may be reduced in more extensive and severe cases [21].

\section{Bronchoscopy, bronchoalveolar lavage and biopsy results}

Mucosal edema and hyperemia are the most typical findings [12, 16, 17]. Suppurative bronchitis is frequent, and in these instances chronic purulent expectoration is the main symptom [10, 17]. Tracheal or bronchial strictures have been described due to extensive submucosal fibrosis $[17,19]$, inflammatory nodules [17] or circumferential mucosal infiltration [33]. Bronchial biopsy reveals mucosal hyperplasia [17], thickening of basal membrane and angioectasia [15], cellular infiltrations composed of granulocytes [16], T and B lymphocytes [17] or non-specific chronic inflammatory infiltrates [15]. Although the most typical finding in the bronchoalveolar lavage (BAL) fluid of IBD patients is lymphocytosis, in tracheobronchial involvement BAL fluid may be dominated by neutrophils [17].

The classical form of small airway disease accompanying IBD is bronchiolitis. Non-necrotizing granulomas consisting of epithelioid, multinucle- 
ated giant and scattered mononuclear cells surrounding small bronchioles were described in patients suffering from CD [22, 34-37]. This and other similar findings recall similarities to sarcoidosis [38]; however, the coincidence of classical sarcoidosis with CD is probably incidental. In bronchiolitis related to UC, non-granulomatous inflammation has been found [19, 21, 39]. Diffuse and fibrosing/sclerosing bronchiolitis of severe course has been described in UC [19].

\section{Radiology}

High-resolution computed tomography (HRCT) is useful for confirming bronchiectasis. In bronchiolitis it shows irregular and patchy areas of different attenuation. The expiratory scans may help to show evidence of air-trapping in the involved areas [40].

\section{Prognosis and treatment}

Systemic steroids are the treatment of choice. Edema, cellular infiltrates and granulation typically respond to treatment $[10,16,17,21]$, but high doses are frequently needed. Inhaled steroids are worth trying, especially in milder cases [20,31]. Bronchiectasis, strictures caused by fibrosis of the bronchial or tracheal wall, and deposits of fibrous material do not respond to pharmacological treatment $[9,19]$, although symptoms of bronchiectasis, e.g. productive cough, may improve [9].

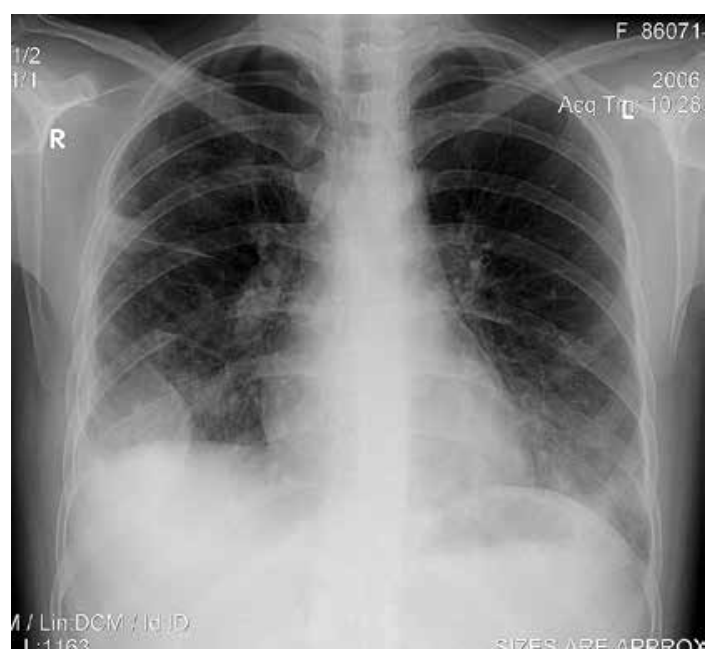

Figure 1. Chest X-ray of a 19-year-old woman with long standing $C D$ treated with mesalazine. Pulmonary infiltrations and right sided pleural effusion are visible. Due to the presence of fever, dry cough and pleural chest pain, pleuropneumonia was diagnosed and antibiotics were introduced. Because of lack of response to antimicrobial treatment she was referred to a pulmonary physician, who recommended withdrawal of mesalazine. After initial improvement, the general and radiological symptoms relapsed (see Figure 2), suggesting the possibility of IBD-related pathology

\section{Interstitial lung disease}

\section{Clinical presentation}

Similarly to tracheobronchial signs and symptoms, interstitial disease may precede the first symptoms of bowel disease by years [41], but most commonly it appears in patients with long-lasting IBD. In addition, interstitial disease signs and symptoms are not related to bowel disease activity and may be present in patients with inactive IBD [42-45]. The clinical course is not characteristic. Asymptomatic lung involvement is possible [46]. General symptoms are frequently reported, and may include malaise, fever or sub-febrile state, loss of weight and arthralgias [42, 47, 48]. The general symptoms seem to be especially frequent in patients with organizing pneumonia (OP) [42, 47] and resemble those described in the course of cryptogenic organizing pneumonia (COP) [49]. Respiratory symptoms include dry cough, breathlessness on exertion or at rest and chest tightness. Expectoration of blood-stained sputum is rare.

\section{Radiology}

Radiological presentations of interstitial lung involvement are quite diverse. Pneumonia-like opacities are very frequent $[15,21,37,50]$, especially in patients with OP $[42,47,51]$ (Figure 1). Multiple pulmonary nodules of different size and location may be present (Figure 2). The bigger coin lesions may resemble metastatic lung disease $[42,43]$. The nodes and small nodules may be located subpleurally [34, 42] (Figure 2). Small cavitations reflecting central necrosis may be present [34]. Tumors with

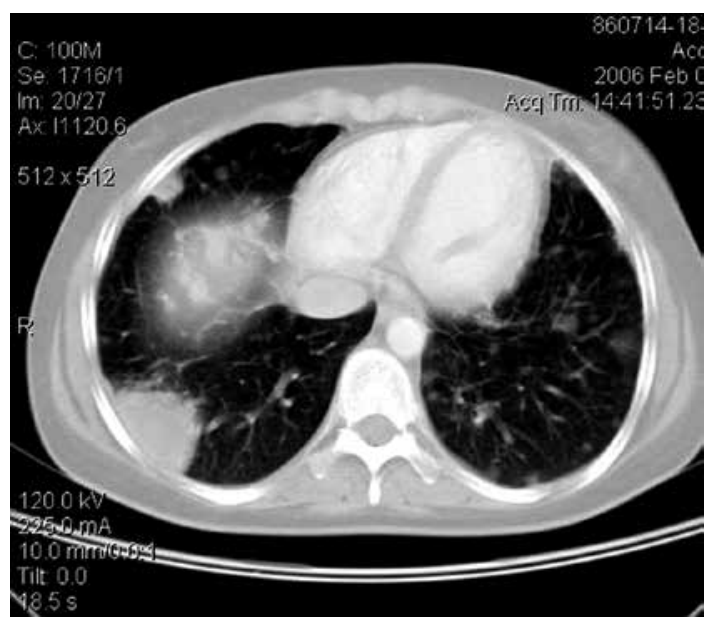

Figure 2. Computed tomography of the same patient performed a few weeks after the presented chest X-ray (Figure 1). Subpleural nodes and nodules are visible. Video-assisted thoracoscopic examination was performed and lung biopsy revealed organizing pneumonia. Clinical and radiological symptoms responded very well to oral steroids and did not relapse until renewed introduction of mesalazine 
central necrosis may resemble granulomatosis with polyangitis (GPA) and may require thorough differentiation with this disease, especially in cases of UC with positive anti-neutrophil cytoplasmic antibodies (ANCA) in the serum [52-57]. Overlapping of UC with GPA in such cases should be considered [58]. Solitary nodules presenting as primary lung tumors may be found [56]. Interstitial pneumonitis may be another radiological presentation. The HRCT scans in these cases reveal ground-glass opacities, alveolar filling or a reticular pattern [40, 59-61]. Extensive fibrosis is rare [62]. Upper lobe fibrosis may resemble TB infection [63]. Some authors report vanishing patterns of radiological lesions not related to treatment or IBD activity [42]. Spontaneous migration of lung opacities has been reported [64]. In the study of Mahadeva et al. [40], which was designed to detect latent respiratory abnormalities in patients with IBD, abnormal HRCT findings were reported in almost all studied patients. The majority had bronchiectasis, air-trapping and "tree-in-bud" patterns. The HRCT findings consistent with alveolitis were present only in $3 \mathrm{pa}$ tients. It reflects the low frequency of interstitial lung disease (ILD) and high frequency of tracheobronchial pathology in patients with $\operatorname{IBD}[59,65]$. More recent reports present similar results [14]. These studies and many case reports show the possibility of coexistence of different forms of lung involvement. It is especially interesting that a high proportion of patients with HRCT abnormality are respiratory-symptom-free $[26,65]$.

\section{Lung function tests}

These may be normal $[43,64]$ or show a mild $[11,66]$ to severe restrictive ventilatory defect $[47$, $51,67]$. Diffusion capacity may be decreased [47], but normal values are also frequently reported $[43,64,66]$. Hypoxemia at rest or on exertion may be present [67]. Munck et al. [68] found that pediatric patients with $C D$, with no signs of pulmonary involvement, have decreased DLCO during exacerbations of the bowel disease. Other authors found DLCO significantly decreased during periods of IBD exacerbations in respiratory-symptom-free adults [27]. About $20 \%$ of patients with pulmonary involvement have inactive bowel disease [65]. This suggests the possibility of a latent asymptomatic lung inflammation in the course of IBD.

\section{Bronchoscopy, BAL and biopsy results}

The BAL cellular pattern is usually abnormal, but changes are not specific. Increased total cell count and mild lymphocytosis are the most typical findings [43, 47, 67]. Some authors reported an increased percentage of BAL eosinophils [64]. Patients without clinical evidence of pulmonary involvement may have alveolar lymphocytosis [69]. Diagnosis is usually confirmed by surgical lung biopsy, but transbronchial peripheral lung biopsy may be sufficient $[11,43,64,67]$. Therefore it is always worth trying as a less invasive method.

The possible pathological patterns are listed in Table I [70-80].

Aseptic lung abscesses [81] and lung bullae [9] may represent destructive forms of pulmonary involvement in patients suffering from IBD.

\section{Inflammatory bowel disease in childhood}

The age of onset of pulmonary involvement may vary in a wide range. The incidence of symptomatic bronchopulmonary involvement in children suffering from IBD seems to be much lower than in

Table I. Possible pathological patterns of IBD-related pulmonary interstitial lung disease. The frequency was estimated arbitrarily on the basis of published case reports and personal expert opinions expressed in review papers $[59,75]$. A systematic study on the real frequency of various patterns has not been performed so far, probably due to the low frequency of IBD-related lung disease

\begin{tabular}{|c|c|c|c|}
\hline Pathological pattern & IBD & Frequency & References \\
\hline Non-specific lymphocytic infiltrations & $C D$ and $U C$ & High & {$[21,51,64,67]$} \\
\hline Organizing pneumonia (OP) & CD and UC & High & {$[47,70-72]$} \\
\hline Non-caseating granulomas & $C D$ & High & {$[38,43,50,73]$} \\
\hline Eosinophilic pneumonia & CD and UC & Moderate & {$[64,74]$} \\
\hline Necrobiotic pulmonary nodules & $C D$ & Moderate & {$[34,75]$} \\
\hline Vasculitis & UC & Moderate & {$[76-78]$} \\
\hline Amyloid nodules & $C D$ & Incidental & {$[79]$} \\
\hline Diffuse alveolar hemorrhage & UC & Incidental & {$[76]$} \\
\hline Usual interstitial pneumonia-like pattern & UC & Incidental & {$[60,62]$} \\
\hline Desquamative interstitial pneumonitis (DIP) & UC & Incidental & {$[80]$} \\
\hline Necrotizing granuloma & $C D$ & Incidental & {$[41]$} \\
\hline Non-specific interstitial pneumonitis (NSIP) & UC & Incidental & {$[61]$} \\
\hline
\end{tabular}


adults [13]. The spectrum of lung pathologies is quite similar, and available reports comprise nodules consisting of non-caseating granulomas [36, 51], cavitating lesions [82], pleuritis [82], lymphocytic infiltrations [15] and organizing pneumonia (OP) in patients with CD [51] and UC [72].

\section{Prognosis and treatment}

Overall prognosis is good. The ILD in patients with IBD responds well to treatment with systemic steroids. Moderate doses of $0.5 \mathrm{mg} / \mathrm{kg}$ of prednisone daily with gradual dose reduction are usually sufficient. However, relapses may occur when the steroid dose is tapered down or withdrawn $[21,67]$. Rare severe interstitial lung fibrosing pneumonitis may be steroid-resistant and fatal $[60,62,83]$. In more severe cases the addition of cyclophosphamide to a high dose of steroid treatment was shown to improve the outcome [67]. An anti-TNF treatment such as infliximab may be an effective alternative to steroids [51, 84]. Spontaneous remission of lung granulomas has also been described [74].

\section{Other forms of respiratory involvement}

Exudative pleuritis, usually eosinophilic, may accompany other lung pathologies [64, 82, 85-89]. Exudative pericarditis with possible life-threatening tamponade may also be present in these patients [87-89]. Pachypleuritis with extensive pleural fibrosis was described in a CD patient [64]. Good responses to steroids have been reported in all cases of pleuritis or pleuropericarditis. Pneumothorax is a rare complication, and was described in a patient suffering from CD-related granulomatous lung disease [90]. An air-leak syndrome (pneumothorax, pneumomediastinum and subcutaneous emphysema) associated with organizing pneumonia pattern was described as an unusual presentation of UC-related bronchopulmonary involvement [91].

Patients with IBD are at increased risk of pulmonary embolism. The risk of thromboembolic complications is 3-4 times higher compared to the general population [92]; therefore thromboembolism should always be considered in cases of acute and unexplained pulmonary symptoms in IBD patients.

\section{Drug-related lung pathology in inflammatory bowel disease patients}

5-Aminosalicylate agents (5-ASA), sulfasalazine and mesalazine, are the mainstay of treatment of IBD. The possibility of pulmonary lesions being induced by these drugs has been acknowledged for decades [93]. However, the incidence of adverse effects in general is low, and in some trials respiratory symptoms have not even been reported [94].
There is a variety of pulmonary changes induced by 5 -ASA, all of them practically indistinguishable from IBD-related lung pathology [95]. The most commonly reported clinico-pathological entities include eosinophilic exudative pleuritis [96-98] and interstitial pneumonitis with the predominance of lymphocytes or eosinophils [93, 97-106]. Poorly formed non-necrotizing granulomas may be found in the lung biopsy [101]. The OP is another possible, albeit less frequent, pathological pattern [107]. Acute phase reaction and peripheral blood eosinophilia may be present $[99,104,106$, 108]. Infiltrations may be asymptomatic [109], but non-productive cough, shortness of breath and general symptoms, most commonly fever, are frequently present. Drug-related lung changes may appear days to years after the start of the treatment. Although 5-ASA-induced lung toxicity is not very common, such a possibility should always be considered at the beginning of the diagnostic process. Withdrawal of the suspected drug may result in a spectacular remission [105, 110, 111]. Severe symptoms, functional impairment, or respiratory insufficiency justify treatment with steroids [91, 102] or, in more problematic cases, immunosuppressive agents [50]. There is one report suggesting dose dependence of mesalamine-induced pulmonary hypersensitivity, based on resolution of lung manifestation after dose reduction [103]. Although 5-ASA-induced lung pathology seems to be group-specific, incidental reports exist showing improvement after shifting from one drug to another [112].

Azathioprine is used for the treatment of more difficult cases of IBD. Interstitial infiltrations due to azathioprine are rare but may be extensive and of severe course. The pathological pattern described in the context of IBD treatment includes interstitial pneumonitis $[113,114]$ and OP [113]. Methotrexate (MTX) is indicated in IBD cases resistant to steroids and purine analogs [115]. It is a drug of acknowledged lung toxicity, which is rare but may be severe and irreversible. Although the risk of interstitial pneumonitis increases with cumulative MTX dose, symptoms may appear even after the first dose, which suggests that immunological mechanisms are involved. In a meta-analysis summarizing the incidence of adverse events in 465 IBD patients treated with MTX, the incidence of interstitial pneumonitis was 0.5\% [116].

Anti-tumor necrosis factor (anti-TNF) agents have become widely used for the treatment of IBD in recent years [117]. Infections and malignancies may occur in patients during such treatment [118]. A number of pulmonary infections have been reported in patients treated with anti-TNF agents, the most important being tuberculosis [119] (Figures $3 \mathrm{~A}$ and $\mathrm{B}$ ). Less frequent ones include lung actinomycosis [120] and invasive aspergillosis 
[121]. Diffuse alveolar hemorrhage has been described after infusion of infliximab in patients with $C D$ [122]. The number of reports on infliximab-induced lung complications may be growing, with the increasing acceptance of this therapeutic option for the treatment of IBD [123]. In the context of both UC and CD, non-specific interstitial pneumonia (NSIP) was described recently $[124,125]$.

\section{Possible links between bowel and lung disease}

Both the colonic and the respiratory epithelia provide the first barrier against microbial agents, antigens and toxins. Exposure to air pollutants, especially to particulate matter (PM), was shown to increase morbidity and mortality related to respiratory and cardiovascular diseases. This effect may be related to the induction of systemic inflammation, which is an important element in the pathogenesis of these diseases. Various pollutants may be swallowed and absorbed from the intestines, potentially inducing systemic and local inflammation. The incidence of IBD has significantly increased in the last five decades, probably reflecting changes in the industrialized environment [126]. The idea of the impact of air pollution on the pathogenesis of IBD is intriguing, but evidence is scarce yet [127].

There are several papers documenting higher frequency of IgE-related and delayed-type hypersensitivity in IBD patients [128-130]. Interestingly, colonic tissue eosinophilia was higher in patients with positive skin prick tests for food allergens
$[130,131]$. Based on such data, it may be suggested that atopy could be a common link between IBD and airway disease (asthma) in some patients. Unfortunately, other data do not support this concept. For instance, asthma and atopy are Th2-mediated diseases, whereas CD is a Th1-mediated pathology [132, 133].

In epidemiological studies, there is a strong association between chronic obstructive pulmonary disease (COPD) and IBD. The risk of COPD in CD patients is 2.7 times, and in UC 1.8 times higher, than in healthy controls [134]. On the other hand, COPD is a strong mortality factor for CD patients (standardized mortality ratio above 2.5) [135]. Smoking, a major risk factor for COPD, increases the risk of $C D$ three-fold [1]. Although the situation is reversed in UC, as active smoking protects against this disease, the risk of UC outbreaks increases in ex-smokers and is higher compared to subjects who have never smoked [1]. An interesting concept of a common origin of these diseases was proposed by a group of Australian authors [136], who speculate on the role of common genetic risk factors (e.g. NOD2), pulmonary and intestinal epithelial barrier disruption due to loss of tight-junctional integrity, similar cytokine profile (TNF, IL-6, IL-13, IL-17) and disruption of the microbiome.

The frequently quoted similarities of granulomatous bowel inflammation in CD and lung sarcoidosis may go beyond simple coincidence. Bowel granulomas in the course of CD may have identical histological composition as lung sarcoid granulomas
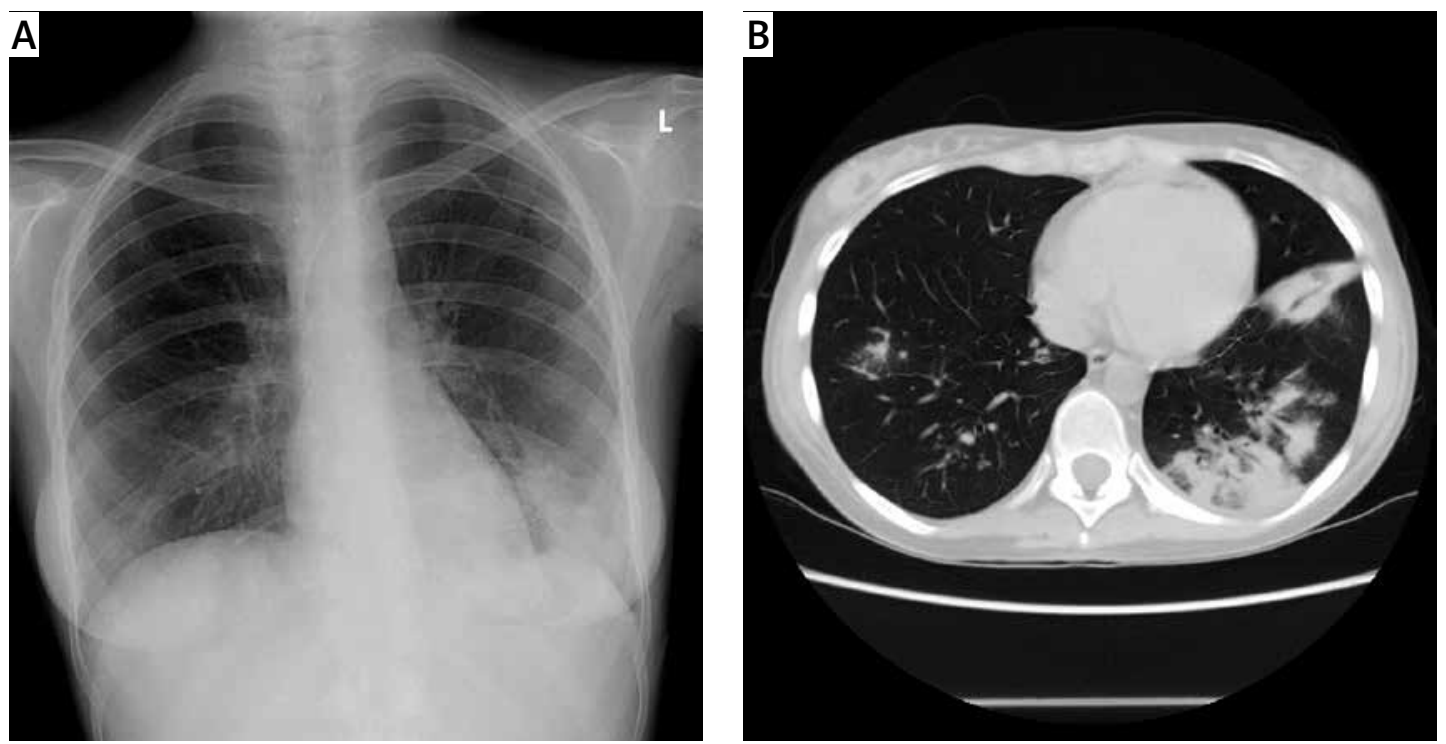

Figure 3. Chest $X$-ray of a young woman treated for $C D$ with infliximab, showing consolidation in the left lower lobe (A) and a CT scan showing bilateral opacities predominantly in the left basal segments (B). She presented with productive cough and fever, non-responsive to empirical antibiotic treatment. The radiological picture and clinical context suggested IBD-related lung disease. Transbronchial lung biopsy was non-diagnostic and the patient refused surgical biopsy. Steroids were introduced but were withdrawn shortly after the bronchoalveolar aspirate appeared positive for Mycobacterium tuberculosis. Note the atypical location of TB lung infiltrations 
$[38,43,50,74]$. BAL fluid of patients with CD-related lung infiltrations shows the predominance of CD4+ over CD8+ cells, similarly to sarcoidosis [133]. Neither IBD nor sarcoidosis is a result of defects in a single major gene or chemical pathway; instead, multiple genes, each contributing a relatively minor effect, are likely to be involved. Recent findings of Fischer et al. [137], who investigated the association of IBD risk loci with sarcoidosis, add further evidence to the postulated common genetic basis of both disorders. In the above context, CD-related bowel inflammation may be a chronic reaction to an unknown environmental antigen (the postulated "sarcoid agent"), which enters the body through the digestive tract. A good example of a common genetic factor is a mutation (single nucleotide polymorphism, SNP) in a gene encoding for nucleotide-binding oligomerization domain containing 2 (NOD2/CARD15). NOD2 is a pattern recognition receptor (PRR), which recognizes a component of the bacterial cell wall (a muramyl dipeptide). This interaction is crucial for a control response to infection at the intestinal mucosa and to regulate autophagy [136]. The defective polymorphic variant (R702W) occurs in about $15 \%$ of CD patients, and is a risk factor of a more severe course [123]. The same functional polymorphic variant was linked to severe chronic sarcoidosis [138].

Overlapping pulmonary and intestinal symptoms in UC and WG and high incidence of various ANCA autoantibodies in IBD patients may suggest the presence of a common autoantigen.

All these possible links gain more value in view of the common ancestry of the digestive tract and tracheobronchial tree, which both originate from the primitive gut. Simultaneous involvement of the biliary duct (which also originates from the primitive gut) in the course of UC with lung and airway involvement is an additional argument for the importance of the above-mentioned relationship $[19,80]$.

\section{Concluding remarks}

Tracheobronchial and pulmonary lesions are relatively rare, but recently more and more frequently recognized extraintestinal manifestations of IBD. Such a possibility should always be kept in mind in the case of unusual clinical symptoms and radiological signs. The spectrum of pathological and radiological patterns is vast. First of all, infection, especially TB, and drug-related changes should be considered in the differential diagnosis. Greater awareness of possible pulmonary manifestations of IBD among both gastroenterologists and pulmonologists may enable better clinical vigilance and form a platform for future research on the common pathological pathways and mutual connections in this area of interest.

\section{Acknowledgments}

The authors would like to thank Kathryn Washburne, Linn Christin Flindal Norseth and Selina Mensah for assistance in linguistic corrections of the manuscript.

\section{Conflict of interest}

The authors declare no conflict of interest.

\section{References}

1. Ponder A, Long MD. A clinical review of recent findings in the epidemiology of inflammatory bowel disease. Clin Epidemiol 2013; 5: 237-47.

2. Yamamoto-Furusho JK. Genetic factors associated with the development of inflammatory bowel disease. World J Gastroenterol 2007; 13: 5594-7.

3. Trikudanathan G, Venkatesh PG, Navaneethan U. Diagnosis and therapeutic management of extra-intestinal manifestations of inflammatory bowel disease. Drugs 2012; 72: 2333-49.

4. Rankin GB, Watts HD, Melnyk CS, et al. National Cooperative Crohn's Disease Study: extraintestinal manifestations and perianal complications. Gastroenterology 1979; 77: 914-20.

5. Mendoza JL, Lana R, Taxonera C, et al. Extraintestinal manifestations in inflammatory bowel disease: differences between Crohn's disease and ulcerative colitis. Med Clin (Barc) 2005; 125: 297-300.

6. Douglas JG, McDonald CF, Leslie MJ et al. Respiratory impairment in inflammatory bowel disease: does it vary with disease activity? Respir Med 1989; 83: 389-94.

7. Ceyhan BB, Karakurt S, Cevik H, et al. Bronchial hyperreactivity and allergic status in inflammatory bowel disease. Respiration 2003; 70: 60-6.

8. Kraft SC, Earle RH, Roesler M, et al. Unexplained bronchopulmonary disease with inflammatory bowel disease. Arch Intern Med 1976; 136: 454-9.

9. Shneerson JM. Lung bullae, bronchiectasis, and Hashimoto's disease associated with ulcerative colitis treated by colectomy. Thorax 1981; 36: 313-4.

10. Butland RJ, Cole P, Citron KM, et al. Chronic bronchial suppuration and inflammatory bowel disease. Q J Med 1981; 50: 63-75.

11. Gabazza EC, Taguchi O, Yamakami T, et al. Bronchopulmonary disease in ulcerative colitis. Intern Med 1992; 31: 1155-9.

12. Spira A, Grossman R, Balter M. Large airway disease associated with inflammatory bowel disease. Chest 1998; 113: 1723-6.

13. Peradzyńska J, Krenke K, Lange J, et al. Low prevalence of pulmonary involvement in children with inflammatory bowel disease. Respir Med 2012; 106: 1048-54.

14. Desai D, Patil S, Udwadia Z, Maheshwari S, Abraham P, Joshi A. Pulmonary manifestations in inflammatory bowel disease: a prospective study. Indian I Gastroenterol 2011; 30: 225-8.

15. Valetta E, Bertini M, Sette L, et al. Early bronchopulmonary involvement in Crohn disease: a case report. BMC Gastroenterol 2001; 1: 13.

16. Iwama T, Higuchi T, Imajo M, et al. Tracheo-bronchitis as a complication of Crohn's disease - a case report. Jpn J Surg 1991; 21: 454-7.

17. Kuźniar T, Sleiman C, Brugière O, et al. Severe tracheobronchial stenosis in a patient with Crohn's disease. Eur Respir J 2000; 15: 209-12. 
18. Kar S, Thomas SG. A case of tracheobronchitis in ulcerative colitis: a review of literature. Clin Respir J 2009; 3: 51-4.

19. Wilcox P, Miller R, Miller G, et al. Airway involvement in ulcerative colitis. Chest 1987; 92: 18-22.

20. Hamada S, Ito Y, Imai S, Oguma T, Niimi A, Mishima M. Effect of inhaled corticosteroid therapy on CT scan-estimated airway dimensions in a patient with chronic bronchitis related to ulcerative colitis. Chest 2011; 139: 930-2.

21. Desai SJ, Gephardt GN, Stoller JK. Diffuse panbronchiolitis preceding ulcerative colitis. Chest 1989; 95: 1342-4.

22. Vandenplas O, Casel S, Delos M, et al. Granulomatous bronchiolitis associated with Crohn's disease. Am J Respir Crit Care Med 1998; 158: 1676-9.

23. Domej W, Kullnig P, Petritsch W, et al. Colobronchial fistula: a rare complication of Crohn's colitis. Am Rev Respir Dis 1990; 142: 1225-7.

24. Steel A, Dyer NH, Matthews HR. Cervical Crohn's disease with oesophago-pulmonary fistula. Postgrad Med J 1988; 64: 706-9.

25. Eaton TE, Lambie N, Wells AU. Bronchiectasis following colectomy for Crohn's disease. Thorax 1998; 53: 529-31.

26. Mikhailova ZF, Levchenko SV, Karagodina I, Bariov VV. Pulmonary disorders in patients with chronic inflammatory bowel disease. Eksp Klin Gastroenterol 2011; 3: 54-9.

27. Hecievhyagil SS, Yalniz M, Seckin Y. Alterations in the pulmonary function tests of inflammatory bowel diseases. Turk J Gastroenterol 2011; 22: 293-9.

28. Neilly JB, Main AN, McSharry S, et al. Pulmonary abnormalities in Crohn's disease. Respir Med 1989; 83: 487-91.

29. Louis E, Louis R, Drion V, et al. Increased frequency of bronchial hyperresponsiveness in patients with inflammatory bowel disease. Allergy 1995; 50: 729-33.

30. Malerba M, Ragnoli B, Buffoli L, et al. Exhaled nitric oxide as a marker of lung involvement in Crohn disease. Int J Immunopathol Pharmacol 2011; 24: 1119-24.

31. Louis E, Louis R, Shute J, et al. Bronchial eosinophilic infiltration in Crohn's disease in the absence of pulmonary disease. Clin Exp Allergy 1999; 29: 660-6.

32. Levo $Y$, Shalit $M$, Wollner $S$, et al. Serum IgE levels in patients with inflammatory bowel disease. Ann Allergy 1986; 56: 85-7.

33. Nakamura M, Inoue T, Ishida A, Miyazu YM, Kurimoto $N$ Miyazawa T. Endobronchial ultrasonography and mag netic resonance imaging in tracheobronchial stenosis from ulcerative colitis. J Bronchology Interv Pulmonol 2011; 18: 84-7.

34. Freeman HJ, Davis JE, Prest ME, et al. Granulomatous bronchiolitis with necrobiotic pulmonary nodules in Crohn's disease. Can J Gastroenterol 2004; 18: 687-90.

35. Trow TK, Morris DG, Miller CR, et al. Granulomatous bronchiolitis of Crohn's disease successfully treated with inhaled budesonide. Thorax 2009; 64: 546-7.

36. Pain-Prado E, Rais A, Madhi F, Orzechowski C, Dubern B, Epaud R. Pulmonary and hepatic nodular lesions precede the diagnosis of Crohn disease in an 8-yearold girl: a case study and review of the literature. Acta Paediatr 2012; 101: e86-9.

37. Lu DG, Ji XQ, Zhao Q, Zhang CQ, Li ZF. Tracheobronchial nodules and pulmonary infiltrates in a patient with Crohn's disease. World J Gastroenterol 2012; 18: 5633-7.

38. Fellermann K, Stahl M, Dahlhoff K, et al. Crohn's disease and sarcoidosis: systemic granulomatosis? Eur J Gastroenterol Hepatol 1997; 9: 1121-4.
39. Ward H, Fisher KL, Waghray R, et al. Constrictive bronchiolitis and ulcerative colitis. Can Respir J 1999; 6 197-200.

40. Mahadeva R, Walsh G, Flower CDR, et al. Clinical and radiological characteristics of lung disease in inflammatory bowel disease. Eur Respir J 2000; 15: 41-8.

41. Shulimzon T, Rozenman J, Perelman M, et al. Necrotizing granulomata in the lung preceding colonic involvement in 2 patients with Crohn's disease. Respiration 2007; 74: 698-702.

42. Piotrowski WJ, Zieliński KW, Kozłowska A, et al. Atypical lung changes in a 19-year-old woman with Crohn's disease. Lung 2007; 185: 189-90.

43. Golpe R, Mateos A, Pérez-Valcárcel J, et al. Multiple pulmonary nodules in a patient with Crohn's disease. Respiration 2003; 70: 306-9.

44. Lucero PF, Frey WC, Shaffer RT, et al. Granulomatous lung masses in an elderly patient with inactive Crohn's disease. Inflamm Bowel Dis 2001; 7: 256-9.

45. Jang EC, Choi SJ, Cho JH, et al. Organizing pneumonia presenting after ulcerative colitis remission. J Thorac Dis 2013; 5: E71-3.

46. Rehman T, Ali J, Lopez FA. A 61-year-old man with asymptomatic, bilateral lung masses. J La State Med Soc 2008; 160: 309-14

47. Carratù $P$, Dragonieri S, Nocerino MC, et al. A case of cryptogenic organizing pneumonia occurring in Crohn's disease. Can Respir J 2005; 12: 437-9.

48. Adachi $\mathrm{Y}$, Hinoda $\mathrm{Y}$, Takahashi $\mathrm{H}$, et al. Rheumatoid arthritis associated with ulcerative colitis. J Gastroenterol 1996; 31: 590-5.

49. Cordier JF. Cryptogenic organizing pneumonia. Eur Respir J 2006; 28: 422-46.

50. Calder CJ, Lacy D, Raafat F, et al. Crohn's disease with pulmonary involvement in a 3 year old boy. Gut 1993; 34: 1636-8

51. Krishnan S, Banquet A, Newman L, et al. Lung lesions in children with Crohn's disease presenting as nonresolving pneumonias and response to infilximab therapy. Pediatrics 2006; 117: 1441-3.

52. Kedziora JA, Wolff M, Chang J. Limited form of Wegener's granulomatosis in ulcerative colitis. Am J Roentgenol Radium Ther Nucl Med 1975; 125: 127-33.

53. Saxon A, Shanahan F, Landres C, et al. A distinct subset of antineutrophil cytoplasmic antibodies is associated with inflammatory bowel disease. J Allergy Clin Immunol 1990; 86: 202-10.

54. Kasuga A, Mandai Y, Katsuno T, et al. Pulmonary complications resembling Wegener's granulomatosis in ulcerative colitis with elevated proteinase- 3 anti-neutrophi cytoplasmic antibody. Intern Med 2008; 47: 1211-4.

55. Elzouki EN, Eriksson S, Löfberg R, et al. The prevalence and clinical significance of alpha-1-antitrypsin deficiency (PiZ) and ANCA specificities (proteinase 3, BPI) in patients with ulcerative colitis. Inflamm Bowel Dis 1999; 5: 246-52

56. Coonar AS, Hwang DM, Darling G. Pulmonary involvement in inflammatory bowel disease. Ann Thorac Surg 2007; 84: 1748-50.

57. Talwar A, Kunst H, Ngatchu T, Trotter S. A case presentation of a pulmonary complication of ulcerative colitis. BMJ Case Rep 2013; 2013. Pii:bcr0220125806.

58. Ouazzani A, Sokolow Y, Hanebaly $M$, et al. Pulmonary granulomatous necrotizing vasculitis: an extra-intestinal manifestation of ulcerative colitis or Wegener's granulomatosis? Rev Med Brux 2011; 32: 93-7.

59. Black H, Mednoza M, Murin S. Thoracic manifestations of inflammatory bowel disease. Chest 2007; 131: 524-32. 
60. Chikano S, Sawada K, Ohnishi K, et al. Interstitial pneumonia accompanying ulcerative colitis. Intern Med 2001; 40: 883-6.

61. Ikehara N, Fujimoto K, Sadohara J, et al. Interstitial pneumonia associated with ulcerative colitis: high-resolution computed tomography and pathologic findings. J Thorac Imaging 2013; 28: W21-3.

62. Marten K, Fend F, Hautmann $\mathrm{H}$, et al. Fatal acute exacerbation of usual interstitial pneumonia in ulcerative colitis. Brit J Radiol 2005; 78: 762-6.

63. Singh R, Sundaram P, Joshi JM. Upper lobe fibrosis in ulcerative colitis. J Assoc Physicians India 2003; 51: 515-7.

64. Faller M, Gasser B, Massard G, et al. Pulmonary migratory infiltrates and pachypleuritis in a patient with Crohn's disease. Respiration 2000; 67: 459-63.

65. Songur N, Songur Y, Tuzun M, et al. Pulmonary function tests and high-resolution $\mathrm{CT}$ in the detection of pulmonary involvement in inflammatory bowel disease. J Clin Gastroenterol 2003; 37: 292-8.

66. Hilling GAL, Robertson DAF, Chalmers AH, et al. Unusual pulmonary complication of ulcerative colitis with a rapid response to corticosteroids: case report. Gut 1994; 35: 847-8.

67. Hotermans G, Benard A, Guenanen H, et al. Nongranulomatous interstitial lung disease in Crohn's disease. Eur Respir J 1996; 9: 380-2.

68. Munck A, Murciano D, Pariente R, et al. Latent pulmonary function abnormalities in children with Crohn's disease. Eur Respir J 1995; 8: 377-80.

69. Wallaert B, Colombel JF, Tonnel AB, et al. Evidence of lymphocyte alveolitis in Crohn's disease. Chest 1985; 87: 363-7.

70. Gabazza EC, Taguchi O, Yamakami T, et al. Bronchopulmonary disease in ulcerative colitis. Intern Med 1992; 31: 1155-9.

71. Swinburn CR, Jackson GJ, Cobden I, et al. Bronchiolitis obliterans organizing pneumonia in a patient with ulcerative colitis. Thorax 1988; 43: 735-6.

72. Mahajan L, Kay M, Wyllie R, et al. Ulcerative colitis presenting with bronchiolitis obliterans organizing pneumonia in a pediatric patient. Am J Gastroenterol 1997; 92: $2123-4$

73. Puntis JWL, Tarlow MJ, Raafat F, et al. Crohn's disease of the lung. Arch Dis Child 1990; 65: 1270-1.

74. Sheehan RE, English J, Wittmann R, et al. Levitating consolidation in eosinophilic lung disease. J Thorac Imaging 2003; 18: 45-7.

75. Camus P, Colby TV. The lung in inflammatory bowel disease. Eur Respir J 2000; 15: 5-10.

76. Bar-Dayan Y, Ben-Zikrie S, Fraser G, et al. Pulmonary alveolar hemorrhage in a patient with ulcerative colitis and primary sclerosing cholangitis. IMAJ 2002; 4: 464-5.

77. Collins WJ, Bendig DW, Taylor WF. Pulmonary vasculitis complicating childhood ulcerative colitis. Gastroenterology 1979; 77: 1091-3.

78. Sargent D, Sessions JT, Fairman RP. Pulmonary vasculitis complicating ulcerative colitis. South Med J 1985; 78: 624-5.

79. Beer TW, Edwards CW. Pulmonary nodules due to reactive systemic amyloidosis (AA) in Crohn's disease. Thorax 1993; 48: 1287-8.

80. Teague WG, Sutphen JL, Fechner RE. Desquamative interstitial pneumonitis complicating inflammatory bowel disease of childhood. J Pediatr Gastroenterol Nutr 1985; 4: 663-7.

81. André MF, Piette JC, Kémény JL, et al. Aseptic abscesses: a study of 30 patients with or without inflammatory bowel disease and review of the literature. Medicine (Baltimore) 2007; 86: 145-61.

82. Vadlamudi NB, Navaneethan U, Thame KA, Kelly DR, Dimmitt RA, Harris WT. Crohn's disease with pulmonary manifestations in children: 2 case reports and review of the literature. J Crohns Colitis 2013; 7: e85-92.

83. McKee AL, Rajapaksa A, Kalish PE, et al. Severe interstitial pulmonary fibrosis in a patient with chronic ulcerative colitis. Am J Gastroenterol 1983; 78: 86-9.

84. Alrashid Al, Brown RD, Mihalov ML, et al. Crohn's disease involving the lung: resolution with infliximab. Dig Dis Sci 2001; 46: 1736-9.

85. Grantham JG, Meadows JA 3rd, Gleich GJ. Chronic eosinophilic pneumonia. Evidence for eosinophil degranulation and release of major basic protein. Am J Med 1986; 80: 89-94.

86. Rosenbaum AJ, Murphy PJ, Engel JJ. Pleurisy during the course of ulcerative colitis. J Clin Gastroenterol 1983; 5: 517-21.

87. Gonzalez Martin T, Dapena Vielba F, Ergueta Martin P, et al. Acute pleuropericarditis and cardiac tamponade as extraintestinal complications of ulcerative colitis. An Med Interna 1990; 7: 581-4.

88. Stajer D, Gorjup V. Myopericarditis, pleuritis and deep venous thrombosis in ulcerative colitis masquerading as pulmonary embolism. Intensive Care Med 1996; 22: 1134-5.

89. Orii S, Chiba T, Nakadate I, et al. Pleuropericarditis and disseminated intravascular coagulation in ulcerative colitis. J Clin Gastroenterol 2001; 32: 251-4.

90. Smith PA, Crampton JR, Pritchard S, et al. Pneumothorax as a presenting feature of granulomatous disease of the lung in a patient with Crohn's disease. Eur J Gastroenterol Hepatol 2009; 21: 237-40.

91. Aydogdu M, Gursel G, Ozyilmaz E, Akyurek N, Memis L. A case of ulcerative colitis complicated with bronchiolitis obliterans organizing pneumonia (BOOP) and air leak syndrome. Turk J Gastroenterol 2012; 23: 590-5.

92. Bernstein CN, Blanchard JF, Houston DS, et al. The incidence of deep venous thrombosis and pulmonary embolism among patients with inflammatory bowel disease. Thromb Haemost 2001; 85: 430-4.

93. Yaffe BH, Korelitz BI. Sulfasalazine pneumonitis. Am J Gastroenterol 1983; 78: 493-4.

94. Brimblecombe R. Mesalazine a global safety evaluation. Scan J Gastroenterol Suppl 1990; 172: 66.

95. Kacprzak A, Siemion-Szcześniak I, Szturmowicz M, Bestry I, Langfort R, Kuś J. Pulmonary pathology in patients with ulcerative colitis treated with mesalazine - a challenging and complex diagnostic problem. Case series and literature review. Pneumonol Alergol Pol 2014; 82: 368-76.

96. Trisolini R, Dore R, Biagi F, et al. Eosinophilic pleural effusion due to mesalamine. Report of a rare occurrence. Sarcoidosis Vasc Diffuse Lung Dis 2000; 17: 288-91.

97. Sesin GP, Mucciardi N, Almeida S. Mesalamine-associated pleural effusion with pulmonary infiltration. Am J Health Syst Pharm 1998; 55: 2304-5.

98. Actis GC, Ottobrelli A, Baldi S, et al. Mesalamine-induced lung injury in a patient with ulcerative colitis and a confounding autoimmune background: a case report. Mt Sinai J Med 2005; 72: 136-40.

99. Bielecki JW, Avar S, Joss R. Sulfasalazine-induced pulmonary infiltrates and Legionella pneumonia. Schweiz Med Wochenschr 2000; 25: 1078-83.

100. Jain N, Petruff C, Bandyopadhyay T. Mesalamine lung toxicity. Conn Med 2010; 74: 265-7. 
101. Foster RA, Zander DS, Mergo PJ, et al. Mesalaminerelated lung disease: clinical, radiographic, and pathologic manifestations. Inflamm Bowel Dis 2003; 9: 308-15.

102. Haralambou G, Teirstein AS, Gil J, et al. Bronchiolitis obliterans in a patient with ulcerative colitis receiving mesalamine. Mt Sinai J Med 2001; 68: 384-8.

103. Sossai P, Cappellato MG, Stefani S. Can a drug-induced pulmonary hypersensitivity reaction be dose-dependent? A case with mesalamine. Mt Sinai J Med 2001; 68: 389-95.

104. Bitton A, Peppercorn MA, Hanrahan JP, et al. Mesalamine-induced lung toxicity. Am J Gastroenterol 1996; 91: 1039-40.

105. Tanigawa K, Sugiyama K, Matsuyama H, et al. Mesalazine-induced eosinophilic pneumonia. Respiration 1999; 66: 69-72.

106. Kim JH, Lee JH, Koh ES, et al. Acute eosinophilic pneumonia related to a mesalazine suppository. Asia Pac Allergy 2013; 3: 136-9.

107. Ulubas B, Sahin G, Ozer C, et al. Bronchiolitis obliterans organizing pneumonia associated with sulfasalazine in a patient with rheumatoid arthritis. Clin Rheumatol 2004; 23: 249-51.

108. Wędrychowicz A, Tomasik P, Pieczarkowski S, Kowalska-Duplaga K, Grzenda-Adamek Z, Fyderek K. Clinical value of serum eosinophilic cationic protein assess ment in children with inflammatory bowel disease. Arch Med Sci 2014; 10: 1142-6.

109. Gabazza EC, Taguchi O, Yamakami T, et al. Pulmonary infiltrates and skin pigmentation associated with sulfasalazine. Am J Gastroenterol 1992; 87: 1654-7.

110. Salerno SM, Ormseth EJ, Roth BJ, et al. Sulfasalazine pulmonary toxicity in ulcerative colitis mimicking clinical features of Wegener's granulomatosis. Chest 1996; 110: 556-9.

111. Moss SF, Ind PW. Time course of recovery of lung function in sulphasalazine-induced alveolitis. Respire Med 1991; 85: 73-5.

112. Uittenbogaart SB, Klemt-Kropp M. Mesalazine and sulphasalazine for Crohn's disease: few indications, severe adverse reactions. Ned Tijdschr Geneeskd 2011; 155: A3842.

113. Ananthakrishnan AN, Attila T, Otterson MF, et al. Severe pulmonary toxicity after azathioprine/6-mercaptopurine initiation for the treatment of inflammatory bowel disease. J Clin Gastroenterol 2007; 41: 682-8.

114. Nagy F, Molnar T, Makula E, et al. A case of interstitial pneumonitis in a patient with ulcerative colitis treated with azathioprine. World J Gastroenterol 2007; 14: 316-9.

115. Dziurkowska-Marek A, Marek T. Methotrexate in the treatment of inflammatory bowel disease. Prz Gastroenterol 2011; 6: 225-33.

116. Schröder O, Stein J. Low dose methotrexate in inflammatory bowel disease: current status and future directions. Am J Gastroenterol 2003; 98: 530-7.

117. Kawalec P, Mikrut A, Wiśniewska N, Pilc A. Tumor necrosis factor-alpha antibodies (infliximab, adalimumab and certolizumab) in Crohn's disease: systematic review and meta-analysis. Arch Med Sci 2013: 9: 765-79.

118. Lees CW, Ali A, Thompson Al, et al. The safety profile of anti-TNF therapy in inflammatory bowel disease in clinical practice: analysis of 620 patient-years follow-up. Aliment Pharmacol Ther 2009; 29: 286-97.

119. Mayordomo L, Marenco JL, Gomez-Mateos J, et al. Pulmonary military tuberculosis in a patient with
anti-TNF-alpha treatment. Scan J Rheumatol 2002; 31: 44-5.

120. Cohen RD, Bowie WR, Enns R, et al. Pulmonary actinomycosis complicating infliximab therapy for Crohn's disease. Thorax 2007; 62: 1013-4.

121. Warris A, Bjørneklett A, Gaustad P. Invasive pulmonary aspergillosis associated with infliximab therapy. N Engl J Med 2001; 344: 1099-100.

122. Panagi S, Palka W, Korelitz BI, et al. Diffuse alveolar hemorrhage after infliximab treatemnt of Crohn's disease. Inflamm Bowel Dis 2004; 10: 274-7.

123. Pytrus T, Iwańczak B. Growth retardation in pediatric inflammatory bowel diseases - pathogenesis and treatment. Prz Gastroenterol 2013; 8: 86-92.

124. Sen S, Peltz C, Jordan K, Boes TJ. Infliximab-induced nonspecific interstitial pneumonia. Am J Med Sci 2012; 344: 75-8

125. Caccaro R, Savarino E, D'Inca R, Sturniolo GC. Noninfectious interstitial lung disease during infliximab therapy: case report and literature review. World J Gastroenterol 2013; 19: 5377-80.

126. Lakatos PL. Recent trends in the epidemiology of inflammatory bowel disease: up or down? World J Gastroenterol 2006; 12: 6102-8.

127. Beamish LA, Osornio-Vargas AR, Wine E. Air pollution: an environmental factor contributing to intestinal disease. J Crohns Colitis 2011; 5: 279-86.

128. D’Arienzo A, Manguso R, Scarpa R, et al. Ulcerative colitis, seronegative spondyloarthropathies and allergic diseases: the search for a link. Scand J Gastroenterol 2002; 37: 1156-63.

129. Myrelid P, Dufmats M, Lilja I, et al. Atopic manifestations are more common in patients with Crohn disease than in the general population. Scand J Gastroenterol 2004; 39: 731-6.

130. D’Arienzo A, Manguso F, Astarita C, et al. Allergy and mucosal eosinophil infiltrate in ulcerative colitis. Scand J Gastroenterol 2000; 35: 624-31.

131. Tzanakis NE, Tsiligianni IG, Siafakas NM. Pulmonary involvement and allergic disorders in inflammatory bowel disease. World J Gastroenterol 2010; 21: 299-305.

132. Kumawat AK, Strid H, Tysk C, Bohr J, Hörnquist EH. Microscopic colitis patients demonstrate a mixed Th17/ Tc17 and Th1/Tc1 mucosal cytokine profile. Mol Immunol 2013; 55: 355-64.

133. Smiéjan JM, Cosnes J, Chollet-Martin S, et al. Sarcoid-like lymphocytosis of the lower respiratory tract in patients with active Crohn's disease. Ann Intern Med 1986; 104: 17-21.

134. Ekbom A, Brandt L, Granath F, Lofdahl CG, Egesten A. Increased risk of both ulcerative colitis and Crohn's disease in a population suffering from COPD. Lung 2008; 186: 167-72.

135. Duricova D, Pedersen N, Elkjaer F, Gamborg M, Munkholm P, Jess T. Overall and cause-specific mortality in Crohn's disease: a meta-analysis of population-based studies. Inflamm Bowel Dis 2010; 16: 347-53.

136. Keely S, Talley NJ, Hansbro PM. Pulmonary-intestinal cross-talk in mucosal inflammatory disease. Mucosal Immunol 2012; 5: 7-18.

137. Fischer A, Nothnagel M, Franke A, et al. Association of inflammatory bowel disease risk loci with sarcoidosis, and its acute and chronic subphenotypes. Eur Respir J 2011; 37: 610-6.

138. Sato H, Williams HR, Spagnolo P, et al. CARD15/NOD2 polymorphisms are associated with severe pulmonary sarcoidosis. Eur Respir J 2010; 35: 324-30. 